\title{
A Critical Analysis of Substance Abuse by Prison Inmates in Nigeria
}

\author{
Ugwuoke Kelvin Abuchi ${ }^{1 *}$ and Mfon Fintan Bassey ${ }^{2}$ \\ ${ }^{1}$ Deputy Superintendent of Prisons, Medium Security Prison, Makurdi, Benue State, Nigeria \\ ${ }^{2}$ Assistant Commander of Narcotics, National Drugs Law Enforcement Agency, Uyo, Akwa-Ibom State, Nigeria
}

Received Date: March 29, 2018; Published Date: April 10, 2018

*Corresponding author: Ugwuoke Kelvin Abuchi, Deputy Superintendent of Prisons, Medium Security Prison, Makurdi, Benue State, Nigeria; Email: ugwukev11@gmail.com

\begin{abstract}
Prisons are known as centres where law breakers are sent to for rehabilitation, reformation and resettlement back to the society. While in prison, inmates are expected to undergo behaviour modification processes from where they will turn out as changed persons when they are eventually released. However, studies and observations have shown that while in prison, some inmates still get access to drugs and abuse them freely. Hence, this study attempts at investigating the abuse of drugs by prisoners in Nigerian Prisons with the aim of unraveling ways through which these substances get into the prison. The study employed the literature review technique to critically analyze issues that lead to this social problem and its implication to public safety and national security. Result from the study shows that inmates mostly used caffeine, alcohol, cigarettes, opioids and marijuana. Result also shows that most of the substances that go into the prison are orchestrated by recalcitrant prison staff and visitors. Recommendations were made on how to strengthen the Nigerian Prison service to cope with the increasing number of inmates who use psychoactive drugs.
\end{abstract}

Keywords: Drugs; Substances; Prison; Prisoners; Reformation

\section{Introduction}

In Nigeria, substance use among prisoners is assuming an alarming dimension as evidenced by the rate of recidivism as well as the prevalence of drug dependent among ex-prisoners. Drug abuse has become a recurrent problem which poses a risk to public safety and by extension, national security. Even with the security apparatus on ground in the various prisons nationwide, these prohibited substances still find their way into the prisons Ugwuoke \& Otodo [1]. With the water tight security set-up in our prisons, it is expected that these substances should be detected; unfortunately, drugs and other psychotropic substances still make their ways through these eagle-eye security into our prison yards. According to a study by Ugwuoke and Otodo [1], the prevalence of drug use among prisoners is high. Different classes of drugs are consumed by prison inmates and this poses a great security to the immediate prison environment, and the nation at large. Apart from posing serious security malady, drug use among inmates also degrades their physical and mental health, and defeats the essence of imprisonment which is for reformation and rehabilitation. Most prisoners who use illicit substances had learned the habit before imprisonment, and when they come into prison, they tend to continue with the habit Ugwuoke and Otodo [1].
It is noteworthy to state at this point that drug use among prison inmates is not only a national problem, but has assumed an international conundrum. Ugwuoke and Otodo [1] noted that substance use has become a problem, and it is increasingly acknowledged on an international level. Many prison inmates that used drugs before imprisonment continue to use them even when they are serving jail terms in prison. Zurhold [2] opined that a considerable number of prisoners not only continue drug use in prison but practice high-risk behaviour such as injecting and needle sharing. Although there are limited data on the drug problem in prisons, studies indicate that up to $50-60 \%$ of drug abusers still use drugs in prison with about one third of them injecting drugs. As reported in the study of Ugwuoke and Otodo [1], imprisonment has been found to impact on an individual's pattern of drug use. 0'Mahony [3] found that $42 \%$ of prison inmates in an Irish prison had used heroin while in prison serving their current sentence. Studies have also found that a significant proportion of the Irish prison population has a history of illicit drug use, and continue to use drugs while in prison (0’Mahony [3], Allwright Barry et al. [4]). However, little is known about the nature of this use and how individuals organize it within the prison setting Dillion [5]. In Nigeria for instance, 
it has been observed that due to the unhindered use of these drugs by prison inmates, many of the inmates who did not use drugs before imprisonment learn drugs use behaviour in prison. Hence, many first offenders that had no drug use experiences prior to imprisonment engage in using substances like cigarette and marijuana. Hence, this study is aimed at analyzing the use of drugs among prison inmates with the view of unraveling how these drugs get into the prison and how to curtail drug use among prison inmates in Nigerian prisons.

\section{Theoretical Underpinning}

This study is premised on Sutherland's [6] differential association theory. This theory according to Gillespie [7] is a prominent socio-logical theory of deviance. Measures identified with the theory of differential association usually explain more of the variance in deviance than do constructs from other microsociological theories of crime (Alarid Burton et al. [8] cited in Gillespie [7]). According to the propositions of this theory, drug-related behavior inside prison is learned in interaction with other persons through a process of communication within intimate personal groups. Learning to abuse drugs in prison is defined by exposure to and association with patterns of behavior. This process of learning the nuances of making, using, selling, or possessing illegal substances in prison involves the mechanisms and cues that are involved in any other learning. It is not necessarily restricted to imitation Gillespie [7]. The theory also posits that learning to abuse drugs and other substances in prison includes grasping the techniques of engaging in this behavior on the inside as well as learning the affiliated motives, drives, rationalizations, and attitudes. The specific direction of motives and drives is learned from definitions (or evaluations) of the legal codes or, in this particular case, the rules of the institution Gillespie [7]. Again, a person is more likely to engage in drug-related activities inside prison when his or her definitions favorable to abusing alcohol or drugs inside prison outweigh his or her definitions to the contrary Sutherland et al. [9].

\section{Drugs Mostly Abused by Prison Inmates in Nigeria}

According to a study by Ugwuoke and Otodo [1], majority of the inmates in Nigeria use more than two drugs. In a study they carried out in Jos prison located in North Central Nigeria, $57.7 \%$ of inmates reported using more than two drugs, while $27.8 \%$ used only two drugs. The study also shows that the majority of poly-drug use involves caffeine, alcohol, tobacco, marijuana and Opioids. Hence, many of the inmates who were reviewed used cigarettes, alcohol, and one other drugs and substances. Again, in addition to the above named drugs, it has been observed that prison inmates also abuse analgesics like codeine and other cough syrups as well as anti-psychotic drugs such as atane, risperidone, and latuda. Owing to the fact that these drugs are easy to conceal, they are easily trafficked into the prison yard.

\section{Ways which Drugs are Smuggled into the Prison in Nigeria}

The various ways through which drugs and other substances find their ways into the prison yard are highlighted below:

Trafficking by Recalcitrant Prison Staff: This is one of the major ways through which drugs and other substances get into the prison yard. Most at times, some bad eggs among the prison staff smuggle these drugs to the inmates owing to the fact that staff do not undergo rigorous security checks before gaining access into the prison yard. It is observed that most staff conceal these drugs to avoid detection, and are smuggled to inmates. Normally, inmates who place order for these drugs usually tip the staff with stipends. Irrespective of the fact that the punishment for trafficking in drugs is outright dismissal, most prison staffers still engage in this illegal trade. It has also been observed that in prisons where staffers are searched, other techniques have been devised to get these drugs into the prison yard. Such techniques include throwing them over the prison wall and picking them up when they get into the prison and so on.

Trafficking by Visitors: Some of the friends and relatives of the inmates who visit also involve in trafficking of drugs and other contrabands. Through exchanges during visits, these illegal substances are passed with some of them concealed in articles, provisions and food items brought to the inmates.

Vehicles Supplying Food and Other Items in the Prison: These drugs are also smuggled into the prison yard through vehicles that supply food, water and other items to the prison. These illicit items are hidden in the vehicles to avoid detection and eventually make their ways into the prison.

Prison Gangs: inmates who go for outside labour usually are drugs couriers. After their labour, they get these drugs and conceal them and when they eventually beat the security, these drugs get into the yard. It has been observed that these inmates conceal drugs in the hems of their clothing, while others go as far as ingesting them or hiding them in their anus to avoid detection.

Inmates who go and Return from Courts: Also, awaiting trial inmates who attend courts also engage in drug trafficking. Most times, this class of inmates pre-arrange with their friends and relatives on how to make these drugs available in courts where they will be handed over and couriered to the prison undetected.

Other ways through which drugs get into the prison include trafficking by ancillary staff such as students on attachment, youth corps members, the religious, legal representatives of the inmates, and other people who gain access to the prison.

\section{Conclusion and Recommendations}

The present study exposes the phenomenon of drugs and substance use among prison inmates in Nigeria. From the discussions in the study, it is obvious that there are many porous ways by which drugs get into the prison which this study 
unravels. This study also shows that many prisoners are neck deep into the use of psychoactive substance such as cigarette, cannabis and opioids, and if appropriate measures are not taken by the government to curb this trend, it may lead to dire consequences for the nation. Therefore, it is concluded that the use of psychoactive substances among admitted prison inmates is assuming a dangerous dimension and hence, the need for immediate intervention to reduce the menace.

In the light of the above, the following recommendations are made:

a. The authority of the Nigerian Prisons service should intensify searching to detect the passage of these illicit substances into the prison.

b. Gadgets and modern drug detection machines should be procured and installed in our prisons.

c. The Nigerian prisons should consider the use of sniffer dogs to sniff out drugs which eventually beat security and get into the prison.

d. Recalcitrant prison staffers that are caught in the act of smuggling drugs into the prison should be punished accordingly.

e. Drug rehabilitation centres should be established in all the prison to provide treatment for inmates who abuse drugs.

\section{References}

1. Ugwuoke KA, Otodo I (2016) A Study of Drug Use Pattern among Inmates of Jos Prison, Nigeria. African Journal for Drugs and alcohol Abuse 15(1): 11-20.

2. Zurhold P (2004) Cocaine use in Europe - A multi-centre study: patterns of use in different groups. Journal of Addiction 10(4): 147155.

3. O Mahony P (1997) Drug Use among Prisoners: An Exploratory Study. The Round Hall Press, Dublin.

4. Allwright S, Barry J, Bradley F, Long J, Thornton L (1999) Hepatitis B, Hepatitis $C$ and HIV in Irish Prisoners: Prevalence and risk. Government Publications, Dublin.

5. Dillion D (2001) Harm Reduction in Prison. Peter Lang AG, European Academic Publishers, Italy.

6. Sutherland EH (1947) Principles of criminology ( $4^{\text {th }}$ edn). JB Lippincott, Philadelphia, USA.

7. Gillespie W (2005) A Multilevel Model of Drug Abuse Inside Prison. The Prison Journal 85(2): 223-246.

8. Alarid LF, Burton VS, Cullen FT (2000) Gender and crime among felony offenders: Assessing the generality of social control and differential association theories. Journal of Research in Crime and Delinquency 37: 171-199.

9. Sutherland EH, Cressey DR, Luckenbill DF (1992) Principles of criminology (11 ${ }^{\text {th }}$ edn). Dix Hills, General Hall, New York, USA.

Your next submission with Juniper Publishers will reach you the below assets

- Quality Editorial service

- Swift Peer Review

- Reprints availability

- E-prints Service

- Manuscript Podcast for convenient understanding

- Global attainment for your research

- Manuscript accessibility in different formats

( Pdf, E-pub, Full Text, Audio)

- Unceasing customer service

Track the below URL for one-step submission

https://juniperpublishers.com/online-submission.php 